\title{
Primary Hemangiopericytoma Arising in Extralobar Pulmonary Sequestration: A Coincidence or Two Rare Disorders?
}

\author{
CHRISTOS F. KAMPOLIS ${ }^{1 *}$, CHRISTOS DAMASKOS ${ }^{2 *}$, ANGELIKI A. LOUKERI ${ }^{3}$, NIKOLAOS GARMPIS ${ }^{2}$, \\ ANNA GARMPI ${ }^{4}$, IOANNIS TOMOS ${ }^{5}$, ELEFTHERIOS SPARTALIS ${ }^{6}$, DIMITRIOS DIMITROULIS ${ }^{2}$, \\ ALEXANDROS PATSOURAS ${ }^{7}$, MAROUSA DOUSKOU $^{8}$, SPYROS A. PAPIRIS $^{5}$ and PERIKLIS TOMOS ${ }^{9}$ \\ ${ }^{1}$ Department of Pathophysiology, University of Athens, Medical School, Athens, Greece; \\ ${ }^{2}$ Second Department of Propedeutic Surgery, Laiko General Hospital, Medical School, \\ National and Kapodistrian University of Athens, Athens, Greece; \\ ${ }^{3}$ Respiratory Care Unit, Sotiria Hospital, General Hospital of Chest Diseases, Athens, Greece; \\ ${ }^{4}$ First Department of Propedeutic Internal Medicine, Laiko General Hospital, Medical School, \\ National and Kapodistrian University of Athens, Athens, Greece; \\ ${ }^{5}$ Second Pulmonary Medicine Department, Attikon University Hospital, \\ National and Kapodistrian University of Athens, Athens, Greece; \\ ${ }^{6}$ N.S. Christeas Laboratory of Experimental Surgery and Surgical Research, \\ Medical School, National and Kapodistrian University of Athens, Athens, Greece; \\ ${ }^{7}$ Medical School, National and Kapodistrian University of Athens, Athens, Greece; \\ ${ }^{8}$ Bioiatriki, Athens, Greece; \\ ${ }^{9}$ Department of Thoracic Surgery, Attikon University Hospital, \\ Athens Medical School, National and Kapodistrian University of Athens, Chaidari, Greece
}

\begin{abstract}
Background/Aim: Extralobar pulmonary sequestration (EPS) is an unusual congenital defect characterized by the presence of non-functioning lung tissue receiving arterial supply from the systemic arteries. Primary hemangiopericytoma (HPC) is an uncommon potentially malignant tumor of vascular origin that usually involves the soft tissue of the extremities or retroperitoneum, but extremely rarely affects the lung. We present the rare case of a primary pulmonary HPC arising in an EPS. Case Report: A 65-yearold woman, with dyspnea and pleuritic chest pain, was referred for further investigation. Radiological evaluation demonstrated a well-circumscribed mass above the right hemidiaphragm, receiving its arterial supply from the descending thoracic aorta. The patient underwent a right
\end{abstract}

This article is freely accessible online.

*These Authors contributed equally to this study.

Correspondence to: Dr. Christos Damaskos, MD, M.Sc., Ph.D., Second Department of Propedeutic Surgery, Laiko General Hospital, National and Kapodistrian University of Athens, Medical School, 17 Agiou Thoma Street, Athens, 11527, Greece. Mobile: +306948467790, e-mail: x_damaskos@yahoo.gr

Key Words: Hemangiopericytoma, extralobar, pulmonary, sequestration. posterolateral thoracotomy and a middle lobectomy. The intraoperative finding was a well-encapsulated solid mass. The histological evaluation described HPC. Results: The patient remains fit and healthy. Conclusion: Pulmonary HPC can arise in EPS. Surgical excision is the treatment of choice.

Extralobar pulmonary sequestration (EPS) is an unusual congenital defect characterized by the presence of nonfunctioning lung tissue that receives its arterial supply from the systemic arteries, most commonly the thoracic aorta. It is separated from the bronchial tree and has its own pleural covering. Primary hemangiopericytoma (HPC) is an uncommon potentially malignant tumor of vascular origin that usually involves the soft tissue of extremities or retroperitoneum, but extremely rarely affects the lung. We herein present the interesting case of a 65-year-old female patient with primary pulmonary HPC arising in an EPS, thereby implying a possible association which has not been previously reported.

\section{Case Report}

A 65-year-old woman, with a 6-month history of dyspnea and pleuritic chest pain, was referred for further investigation of undiagnosed right-sided pleural effusion. She had no relevant medical or family history and had not received any medications recently. 

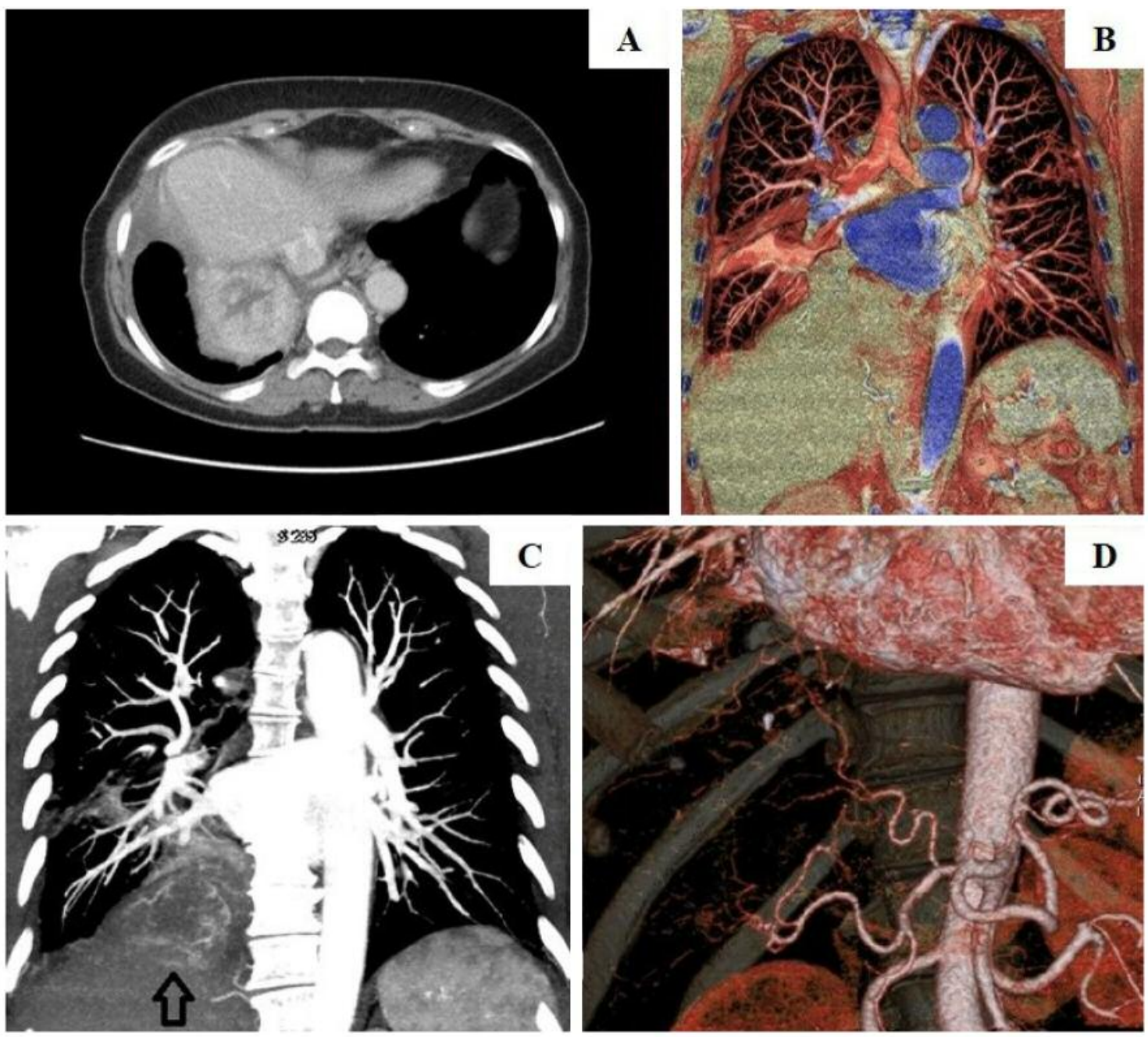

Figure 1. Contrast-enhanced computed tomography $(C T)$ and CT angiography findings of extralobar pulmonary sequestration (EPS). A: A wellcircumscribed mass just above the right hemidiaphragm and a small ipsilateral pleural effusion were depicted by thoracic CT. B: CT angiography confirmed the presence of a solid soft-tissue mass causing local atelectasis of the adjacent lung. $C, D$ : The lesion had a systemic arterial blood supply consisting of small-sized feeding vessels and larger arterial branches which originated from the subdiaphragmatic segment of the abdominal aorta (coronal reconstructed maximum intensity projection). All the above findings were consistent with a diagnosis of EPS.

On admission, she had no additional respiratory or systemic symptoms such as cough, fever, fatigue, hemoptysis or weight loss. There were no signs of cyanosis, finger clubbing, peripheral edema, skin lesions or peripheral lymphadenopathy. Chest auscultation revealed diminished breath sounds in the right lower lung zone, while abdominal examination was insignificant. Apart from a mild normocytic anemia (Ht: 30\%, Hb: $9.4 \mathrm{~g} / \mathrm{dl}$ ), complete blood count, routine biochemistry blood tests and arterial blood gas examination were within normal limits.

Contrast-enhanced thoracic computed tomography (CT) demonstrated a well-circumscribed mass above the right hemidiaphragm, without evidence of calcification or cavitation, and an accompanying pleural effusion (Figure
1A). The diagnosis of pulmonary sequestration was suspected due to the location of the lesion and the heterogeneous enhancement displayed. Multidetector CT angiography was carried out and confirmed that the mass received its arterial supply from the descending thoracic aorta (Figure 1B-D).

The patient underwent a right posterolateral thoracotomy and a tumorectomy with right middle lobectomy. The intraoperative finding was a sizeable well-encapsulated solid mass, without any presence of normal lung tissue in it, which was successfully detached from the surrounding tissues, and the afferent artery was subsequently ligated (Figure 2). The postoperative period was uneventful. Histological examination of the resected specimen showed infiltration by 


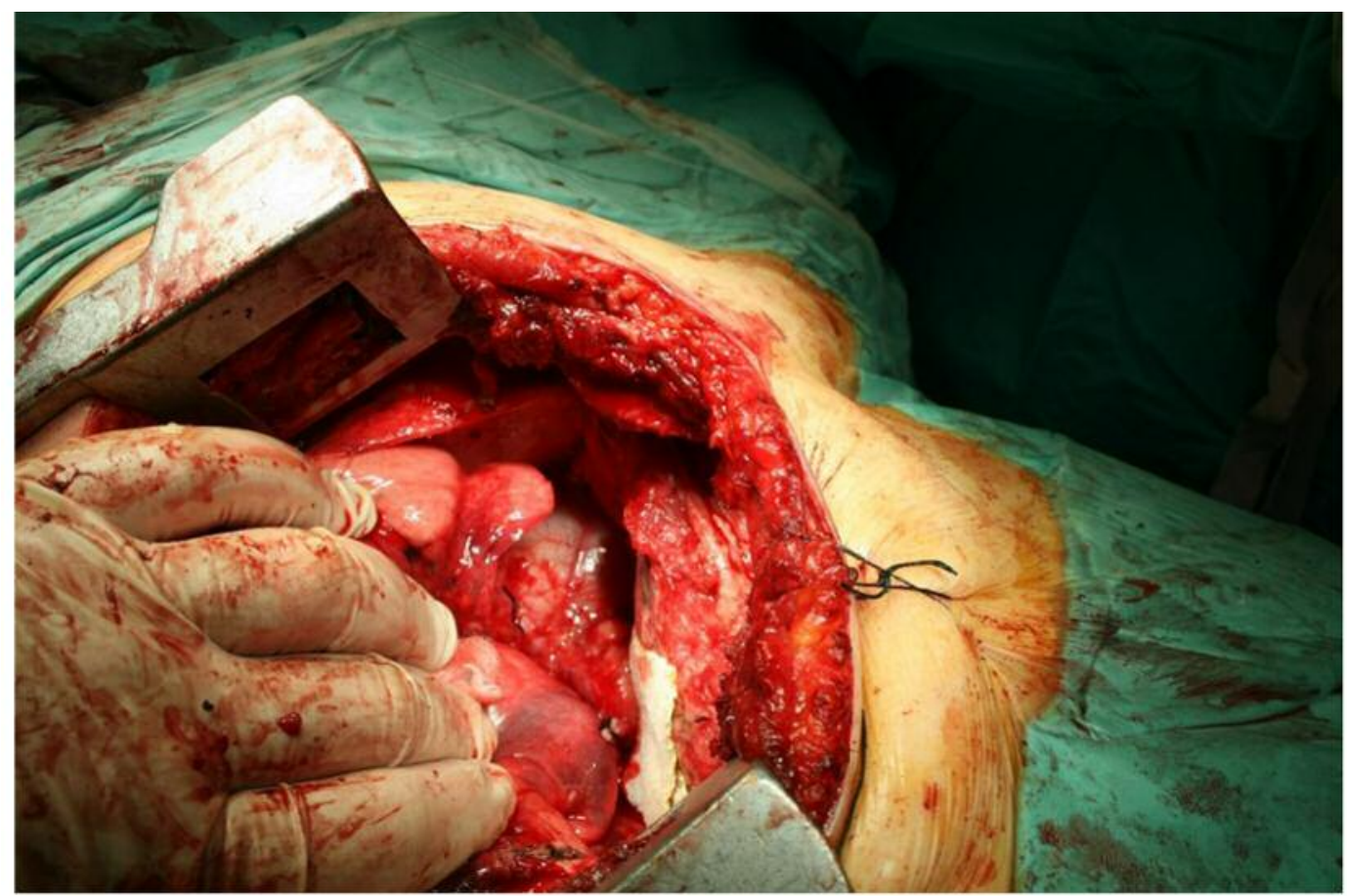

Figure 2. The patient underwent right posterolateral thoracotomy. A sizeable well-encapsulated solid mass was successfully detached from surrounding tissues.

regular tumor cells without atypia. The cells presented with round and spindle-shaped nuclei that surrounded vascular channels and had few mitoses per section. Tumor cells were immunohistochemically positive for vimentin, CD34 and CD99, but negative for smooth muscle actin, cytokeratin 14, epithelial membrane antigen and desmin. Staining for factor VIII antigen was positive in lining endothelial cells, but negative in perivascular cells (Figure 3 ). The diagnosis of primary pulmonary HPC was reliably established based on the above histological findings.

The patient had a significant improvement of her symptoms within the next few months, and remained clinically and radiologically stable, without any signs or symptoms of local tumor recurrence or metastatic disease, 2 years postoperatively.

\section{Discussion}

The term HPC was initially suggested by Stout and Murray in 1942 to describe a rare tumor of vascular origin, mainly composed of capillary pericytes (1). Primary pulmonary localization of this type of neoplasm is extremely rare, can occur at any age and may have malignant potential. Benign or malignant differential diagnosis is almost impossible to establish on the basis of clinical examination or plain chest x-rays. Among 36 cases reported in the literature until 1979
$(2,3)$ and a subsequent case series of 18 patients (4), approximately $40 \%$ to $50 \%$ of patients with pulmonary HPC were asymptomatic at presentation, despite the impressively large size $(\geq 5 \mathrm{~cm})$ of the tumor in up to two-thirds of cases. Non-specific symptoms such as hemoptysis and chest pain were the commonest, while dyspnea or cough were less frequently met. Large-sized, homogenous, soft-tissue masses with round or slightly lobulated margins and infrequent calcification or no sign of atelectasis were characteristic, though not pathognomonic, radiographic features on $\mathrm{x}$-ray $(2,3)$. In later studies, CT scan more accurately described calcification in $10 \%$ of cases and recognized large central areas of low attenuation in large HPCs, as a radiological indicator of malignancy (5).

Pulmonary sequestration accounts for $0.15-6.4 \%$ of all congenital pulmonary anomalies (6). EPS comprises $25 \%$ of sequestrations (7). Most cases (approximately 80\%) of EPS lie between the lower lobe and the diaphragm, are left-sided and occupy the region of the posterior basal segments (6). The characteristic position of the lesion and recurrent lung infections without significant radiographic resolution in childhood or young adulthood makes intrapulmonary sequestration a possible diagnosis. On the contrary, EPS due to lack of communication with the tracheobronchial tree may remain asymptomatic for many years or less frequently present in the neonatal period with more intense clinical 

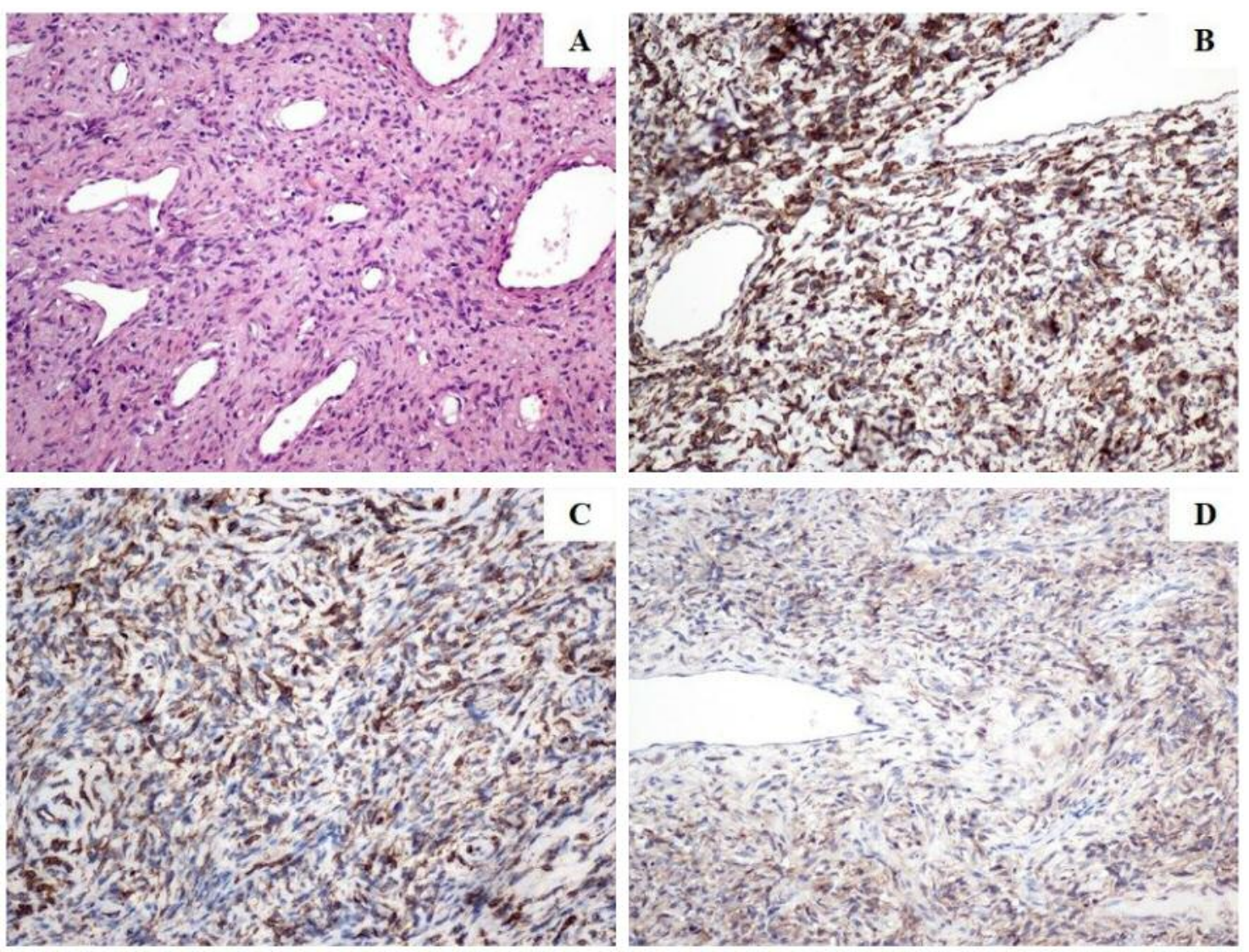

Figure 3. Histological examination of the solid soft-tissue mass resected from the right lower lung lobe. The tumor had a perivascular hemangiopericytomatoid pattern of cellular growth, and vessel dilatation was also observed in eosin-hematoxylin images (100x) (A). Tumor cells were strongly and diffusely positive for vimentin (B), CD34 (C): and CD99 (D) (200x).

manifestations such as respiratory failure, cyanosis, infections and/or recurrent pulmonary hemorrhage (8). Contrastenhanced helical CT scanning with 3-dimensional reconstruction can confirm the suspected diagnosis (9). Conventional or CT arteriography is helpful in differentiating the lesion from other abnormalities of the lung, such as pulmonary arteriovenous fistula, based on the demonstration of systemic arterial blood supply of sequestration (10). Despite the lack of a history of susceptibility to pulmonary infections in our elderly patient, the presence of a wellcircumscribed mass located in the lower lung field determined our decision to proceed to $\mathrm{CT}$ arteriography and 3-dimensional reconstruction imaging.

The therapy for pulmonary sequestrations is controversial. If asymptomatic, they are often left alone. Even though EPS may show spontaneous regression, the latest study suggests that the volume and diameter of systemic feeding arteries of EPS spontaneously decreased within 4 years without treatment in neonatal patients (11). For those patients with recurrent infections or other symptoms, surgery or embolization or both have been recommended (12). Although the incidence of carcinoma is low, its existence has provided an argument for the need for surgery (13).

The occurrence of benign or malignant neoplasms within pulmonary sequestrations is extremely rare. Nine other cases of primary lung cancer (mainly adenocarcinoma or squamous carcinoma) have already been reported in the English literature. The tumor was found to arise within an intralobar sequestration in all but one case (14). Therefore, the etiology of the carcinomas in the sequestration cases may be multifactorial and may include chronic inflammation and irritation.

There is a single published case of vascular tumor, sclerosing hemangioma, arising within an EPS in a young child (15). A more recent study of a small series of surgically removed intraand extrapulmonary sequestrations, revealed hypertensive vascular changes and a possible mechanism of exposure to the elevated pressures of systemic arterial supply was implied (16). Although developmental abnormalities and chronic vascular changes within pulmonary tissue may have a pathogenetic role, 
this extremely rare case of HPC development in EPS might be considered a coincidental association.

Radical surgical excision is the treatment of choice for HPC. Intraoperative and postoperative radiotherapy has been proposed as an innovative approach after complete tumor resection (17). The benefits of radiotherapy as palliative treatment for local recurrence or superior vena cava obstruction or chemotherapy for treating patients with metastatic disease or those for whom surgery is not feasible have not yet been clarified (3). Long-term postoperative observation is highly recommended (5), since primary pulmonary HPC may recur locally (pleura, lung, mediastinum) or distally in up to one-third of cases, usually within the first 1-2 years but rarely more than a decade after surgical excision of the tumor $(4,18)$.

\section{Conflicts of Interest}

All the Authors declare that there is no conflict of interest in regard to this study.

\section{Authors' Contributions}

PT designed the study and was the supervisor. PT, CD and DD performed the surgical operation. CFK and CD contributed equally. CFK and CD wrote the article. AAL, NG, AG, IT, ES and AP collected the data. MD performed radiological evaluations. DD and $\mathrm{SAP}$ revised the article.

\section{Acknowledgements}

The Authors would like to thank Associate Professor Agrogiannis G. for the histopathological examinations.

\section{References}

1 Stout AP and Murray MR: Hemangiopericytoma: A vascular tumor featuring Zimmermann's pericytes. Ann Surg 116(1): 2633, 1942. PMID: 17858068. DOI: 10.1097/00000658194207000-00004

2 Meade JB, Whitwell F, Bickford BJ and Waddington JK: Primary haemangiopericytoma of lung. Thorax 29(1): 1-15, 1974. PMID: 4825550. DOI: 10.1136/thx.29.1.1

3 Shin MS and Ho KJ: Primary hemangiopericytoma of lung: radiography and pathology. AJR Am J Roentgenol 133(6): 10771083, 1979. PMID: 116498. DOI: 10.2214/ajr.133.6.1077

4 Yousem SA and Hochholzer L: Primary pulmonary hemangiopericytoma. Cancer 59(3): 549-555, 1987. PMID: 3791163. DOI: $10.1002 / 1097-0142(19870201) 59: 3<549::$ aid-cncr 2820590332>3.0.co;2-y

5 Halle M, Blum U, Dinkel E and Brugger W: CT and MR features of primary pulmonary hemangiopericytomas. J Comput Assist Tomogr 17(1): 51-55, 1993. PMID: 8419439.

6 Savic B, Birtel FJ, Tholen W, Funke HD and Knoche R: Lung sequestration: Report of seven cases and review of 540 published cases. Thorax 34(1): 96-101, 1979. PMID: 422005. DOI: $10.1136 /$ thx.34.1.96
7 Felker RE and Tonkin IL: Imaging of pulmonary sequestration. Am J Roentgenol 154(2): 241-249, 1990. PMID: 2105007. DOI: 10.2214/ajr.154.2.2105007

8 Akdag A, Arici S, Kaya M and Turgut A: Extralobar pulmonary sequestration as a cause of recurrent pulmonary hemorrhage in a neonate. Arch Argent Pediatr 114(1): e21-e24, 2016. PMID: 26914085. DOI: 10.5546/aap.2016.eng.e21

9 Toya SP, Douskou M, Tomos P and Tzelepis GE: Pulmonary sequestration diagnosed by multidetector computed tomographic angiography. Eur J Cardiothorac Surg 32(3): 535, 2007. PMID: 17643997. DOI: $10.1016 /$ j.ejcts.2007.06.008

10 Ren JZ, Zhang K, Huang GH, Zhang MF, Zhou PL, Han XW, Duan $\mathrm{XH}$ and $\mathrm{Li} \mathrm{Z}$ : Assessment of 64-row computed tomographic angiography for diagnosis and pretreatment planning in pulmonary sequestration. Radiol Med 119(1): 27-32, 2014. PMID: 24234181. DOI: 10.1007/s11547-013-0304-9

11 Yoon HM, Kim EA, Chung SH, Kim SO, Jung AY, Cho YA, Yoon $\mathrm{CH}$ and Lee JS: Extralobar pulmonary sequestration in neonates: The natural course and predictive factors associated with spontaneous regression. Eur Radiol 27(6): 2489-2496, 2017. PMID: 27659701. DOI: 10.1007/s00330-016-4594-x

12 Brown SC, De Laat M, Proesmans M, De Boeck K, Van Raemdonck D, Louw J, Heying R, Cools B, Eyskens B and Gewillig M: Treatment strategies for pulmonary sequestration in childhood: resection, embolization, observation? Acta Cardiol 67(6): 629-634, 2012. PMID: 23393932. DOI: 10.2143/ AC.67.6.2184664

13 Scialpi M, Cappabianca S, Rotondo A, Scalera GB, Barberini F, Cagini L, Donato S, Brunese L, Piscioli I and Lupattelli L: Pulmonary congenital cystic disease in adults. Spiral computed tomography findings with pathologic correlation and management. Radiol Med 115(4): 539-550, 2010. PMID: 20058095. DOI: 10.1007/s11547-010-0467-6

14 Belchis D, Cowan M, Mortman K and Rezvani B: Adenocarcinoma arising in an extralobar sequestration: a case report and review of the literature. Lung Cancer 84(1): 92-95, 2014. PMID: 24560335. DOI: 10.1016/j.lungcan.2014.01.025

15 Ahmetoğlu A, Koşucu P, Imamoğlu M, Reis A, Cay A and Gümele HR: Sclerosing haemangioma arising within extralobar pulmonary sequestration. Pediatr Radiol 33(9): 641-643, 2003. PMID: 12811433. DOI: 10.1007/s00247-003-0946-1

16 Desai S, Dusmet M, Ladas G, Pomplun S, Padley SP, Griffin N, Badreddine J, Goldstraw P and Nicholson AG: Secondary vascular changes in pulmonary sequestrations. Histopathology 57(1): 121-127, 2010. PMID: 20584090. DOI: 10.1111/j.13652559.2010.03586.x

17 Rusch VW, Shuman WP, Schmidt R and Laramore GE: Massive pulmonary hemangiopericytoma. An innovative approach to evaluation and treatment. Cancer 64(9): 1928-1936, 1989. PMID: 2790703. DOI: 10.1002/1097-0142(19891101)64: 9<1928::aid-cncr2820640928>3.0.co;2-y

18 Razzuk MA, Nassur A, Gradner MA, Martin J, Gohara SF and Urschel HC Jr.: Primary pulmonary hemangiopericytoma. J Thorac Cardiovasc Surg 74(2): 227-229, 1977. PMID: 881875.

Received August 2, 2019

Revised August 29, 2019 Accepted September 3, 2019 